\title{
A HIPÓTESE DA LINGUAGEM DO PENSAMENTO DE JERRY FODOR: ALCANCES E LIMITES DE UMA TEORIA DA MENTE
}

\author{
Kleber Bez Birolo Candiotto \\ Pontifícia Universidade Católica do Paraná
}

Resumo: 0 eixo desta investigação é a noção de linguagem inata e interna, proposta por Jerry Fodor, que teve como principal desafio a tradição analítica do século $\mathrm{XX}$, a qual se fundamentou no antimentalismo de Wittgenstein e na sua negação de uma linguagem privada. A hipótese da "linguagem do pensamento" pode ser equivocadamente associada ao conceito de linguagem natural. Por isso, Fodor sugere uma distinção entre tais linguagens, visto que a do pensamento deve ser compreendida como manipulação "interna" de símbolos. Esta noção de "interno" tem gerado controvérsias quando confrontada com a tradição wittgensteiniana. Neste trabalho, apresentamos os alcances e limites da hipótese fodoriana de uma linguagem do pensamento, almejando especificamente discutir o impasse quanto à noção de "interno" suscitado por tal hipótese.

Palavras-chave: mentalismo, linguagem do pensamento, significado, linguagem interna.

Abstract: The axis of this investigation is the notion of the innate and internal language proposed by Jerry Fodor which had as its main chalenge, to surpass the $20^{\text {th }}$ century anatical tradition fundamented on Wittgenstein's anti-mentalism and his negation of a private language. Since Fodor's Language of Thought Hipothesis might be equivocally associated to the concept of natural language, he suggests a distinction between them by considering that the Language of Thought must be understood as an internal manipulation of symbols. However, the term "internal" has generated controversy once confronted with the wittgeinsteinian tradition. Therefore, in this paper, we put forward the wideness of range and the limits of the Fodorian hipothesis of a Language of Thought, especifically with the objective of discussing the impass related to the conception of the adjective "internal" suscitated by such hipothesis.

Keywords: mentalism, language of thought, meaning, internal language. 
Em ciências cognitivas, a Teoria Computacional da Mente trata a mente como um dispositivo que manipula símbolos, pressupondo que, se um processo mental pode ser definido como uma operação sobre símbolos, então existe uma "máquina de Turing"1 operada por uma série de mecanismos que lhe dão condições de realizar um cômputo.

Jerry Fodor, inspirado pelos modelos computacionais, nos quais se pode instalar uma série de linguagens, desde uma "linguagem-máquina”, propõe que todo ser humano dispõe de uma "linguagem residente" inata, o "mentalês" (mentalese), que lhe permite adquirir e operar com as línguas naturais. Nesse caso, o aprendizado de uma língua natural depende inerentemente de uma língua-base, que Fodor nomeia de linguagem do pensamento. Fodor (1975) procurou sustentar sua hipótese da linguagem do pensamento mediante o seguinte raciocínio: os modelos que dispomos para representar os processos cognitivos, ou como se diz, operações mentais, são todos sistemas de representação providos de meios de cálculo (computations); tais sistemas não podem ser eles mesmos as línguas naturais, pois careceriam de um caráter universal para que o cálculo possa ser realizado; por isso, deve haver um sistema primitivo universal inato da linguagem.

Fodor postula uma linguagem do pensamento inata que tem como função a manipulação de símbolos mentais, propiciando assim a "geração" de significados, questão fundamental para a aquisição de uma linguagem natural ou, como também se diz: linguagem pública. Neste artigo, procuramos descrever o desenvolvimento dessa hipótese, assim como destacar os principais limites do programa de pesquisa de Fodor para sustentar sua noção de uma linguagem interna e inata. Porém, antes da exposição da teoria fodoriana de linguagem do pensamento, procuramos elucidar o contexto da elaboração de sua tese, apresentando especialmente os entraves impostos pela tradição wittgnesteiniana. O impasse entre as perspectivas wittgensteiniana e fodoriana de linguagem promoveu novos desafios ao programa de pesquisa de Fodor, entre os quais destacaremos o problema do significado das representações mentais.

\footnotetext{
1 A "máquina de Turing" deve ser entendida como uma máquina imaginária (não necessariamente hipotética), na qual os símbolos de inputs e outputs poderiam equivaler, de acordo com sua programação, a qualquer uma dentre numerosas interpretações sensatas. A ideia é exposta por Alan Turing em seu artigo On Computable Numbers, with an Application to the Entscheidungsproblem. Uma completa exposição sobre a concepção de máquina universal de Turing ver Petzold (2008, p.143-162). Uma síntese sobre o "funcionamento" da máquina de Turing, ver ANDLER (1988, p.35).
} 


\section{Resistência à tradição wittgensteiniana}

O alcance da crítica de Wittgenstein à "linguagem privada", exposta em sua obra póstuma de 1953, Investigações Filosóficas, foi um dos principais motivos da resistência à tese fodoriana de uma linguagem interna e inata. Wittgenstein entende por "linguagem privada" aquela que apenas seu detentor poderia compreender, uma espécie de propriedade particular de seu usuário, o que, por princípio, impede sua tradução para qualquer outra forma de linguagem. "Linguagem privada", na concepção de Wittgenstein, não deve ser confundida com a linguagem empregada por um indivíduo em um contexto solitário e privado, uma vez que, ao "conversar" consigo, este indivíduo já está fazendo uso de uma linguagem previamente adquirida em um contexto intersubjetivo. Uma linguagem é privada quando seus signos têm como referentes questões que apenas o usuário tem acesso e, consequentemente, apenas ele pode saber, tais como vivências subjetivas, sentimentos ou estados mentais. Entretanto, ao questionar sobre a possibilidade da ligação do nome ao nomeado, neste caso especialmente como um indivíduo atribui nomes a suas sensações (sentimentos, vivências subjetivas, etc.), Wittgenstein conclui que uma palavra usada para exprimir uma sensação (dor, por exemplo) não tem como referente direto aquela sensação. Palavras para se referir a sensações não são, a seu ver, designações de objetos particulares obtidos por uma "percepção" interna e privada, pois, ao contrário, seu significado seria também algo também privado e que, portanto, seria sem sentido. Por isso, os nomes dados às sensações não podem sem considerados "nomes" propriamente ditos, uma vez que necessitariam se referir diretamente a "coisas" como seus correlatos. Nas Investigações Filosóficas, o filósofo austríaco menciona que, entre a palavra e a sensação, não há uma conexão direta, mas sim indireta, estabelecida pelo intermédio do comportamento. No §244, Wittgenstein reforça esta conclusão com o exemplo da palavra "dor". A criança, ao se ferir e gritar, é socorrida por um adulto, o qual emite exclamações e, com isso, ensina-lhe um novo comportamento de dor.

Mais adiante, no $\$ 269$, Wittgenstein destaca que existem certos critérios de comportamento para determinar se 1) o indivíduo não compreendeu uma palavra, se 2) ele a compreendeu equivocadamente ou se 3) a compreendeu corretamente. No segundo caso, Wittgenstein define a situação como uma compreensão subjetiva: "poder-se-ia chamar 'linguagem privada' a sons que eu 'pareço compreender', mas que ninguém mais compreende". Mas "linguagem privada", nessa crítica do autor, tem uma 
aplicação mais específica. Por "linguagem privada” em Wittgenstein, em suma, deve-se entender aquela que descreve experiências internas de um sujeito. Entendida assim, apenas este sujeito tem acesso a tal linguagem. Uma linguagem definida nesses termos, segundo o filósofo austríaco, é inexistente ${ }^{2}$.

Para Wittgenstein, há linguagem apenas se ela for determinada por regras de caráter público. Mesmo admitindo que existam experiências privadas, Wittgenstein rejeita qualquer noção de linguagem privada. As sensações ${ }^{3}$ como a dor podem ser privadas, mas a linguagem para expressá-las é sempre pública. A linguagem, para o filósofo austríaco, existe como um jogo, onde as regras devem ser públicas e jogadas intersubjetivamente. No $\S 108$ das Investigaçôes Filosóficas, Wittgenstein compara os jogos linguísticos a jogos em geral, neste caso, ao xadrez. O que possibilita o jogo do xadrez são as regras de movimentos das peças, sendo desnecessário descrever suas propriedades físicas. Semelhante ao xadrez, os jogos linguísticos são praticados por mais de um indivíduo, tendo, portanto, como característica central sua publicidade, uma vez que é uma atividade repetida, generalizada e socialmente compartilhada. Isso é notoriamente apresentado no §109 da obra supracitada, onde Wittgenstein nega a possibilidade de uma regra ser praticada uma única vez por um único indivíduo. Para ele, uma regra é um costume, uma instituição, como afirma no §202: "Por isso, 'seguir uma regra' é uma práxis. E crer estar a seguir a regra não é seguir a regra 'privatim', por que então crer estar a seguir a regra seria o mesmo do que seguir a regra”.

A linguagem, na perspectiva de Wittgenstein, é sempre adquirida por "explicações ostensivas", isto é, pela observação das indicações do comportamento alheio. Vale destacar que Wittgenstein não nega a existência da privacidade do pensamento, isto é, que sua ocorrência se dê internamente, contudo resiste em aceitar o pensamento como uma linguagem privada, da forma sustentada posteriormente por Fodor.

Filósofos de herança wittgensteiniana consideram que as línguas naturais exercem dois papéis indissociáveis: primeiro, o papel da linguagem como um meio para a formulação e ocorrência de processos cognitivos; e o segundo, a linguagem como mediadora da comunicação entre falantes e

\footnotetext{
2 No §262, a refutação da "linguagem privada" é muito clara: "poder-se-ia dizer: quem se deu a si próprio uma explicação privada de uma palavra, tem que, perante o seu foro interior, vincular-se a usar a palavra assim e assim. E como se procede ao vínculo? Devo supor que a pessoa inventa a técnica de aplicação da palavra ou que já a encontrou pronta para ser usada?"

3 A própria palavra "sensação" pertence a uma linguagem de uso comum (pública) e não de uma linguagem exclusiva ao sujeito que possui a sensação, tal como Wittgenstein evoca no §261.
} 
ouvintes. A partir desta indissociabilidade de papeis, instaura-se a noção unicamente pública da linguagem, marcando o tabu das linguagens privadas.

Desde seus primeiros escritos, Fodor procurou realizar uma crítica ao pensamento de Wittgenstein. Na introdução de The Structure of the language de 1964, Fodor apresenta sua recusa à teoria de Wittgenstein como uma explicação racional e científica do comportamento linguístico. Em 1965, no artigo Operationalism and ordinary language, 4 , Fodor classifica polemicamente Wittgenstein e os filósofos por ele influenciados como behavioristas lógicos ${ }^{5}$.

Em The Language of Thought (1975), Fodor rejeita a tradição wittgensteiniana pelo fato de se pautarem na existência de uma única linguagem, aquela que possui caráter público. Segundo ele, esses papéis são desenvolvidos por "linguagens" 6 diferentes: o "mentalês" é empregado para o primeiro papel da linguagem (como um meio para a formulação e ocorrência

\footnotetext{
${ }^{4} \mathrm{O}$ texto original é CHIHARA, C.; FODOR, J. "Operationalism and ordinary language: a critique of Wittgenstein". In: American Philosophical Quarterly, 2, 1965, p. 281-295. Fizemos uso deste texto publicado em FODOR (1981).

5 "Filósofos wittgeinsteinianos têm às vezes negado veementemente que o termo "behaviorismo" seja corretamente empregado no tocante à concepção de que as conexões lógicas do tipo acima citadas existem. Não acreditamos que haja tantos problemas na utilização que fazemos do termo "behaviorismo", mas estamos preparados para justificar nossa terminologia. 0 "Behaviorismo" é, em primeiro lugar, um termo ao qual recorreu uma escola de psicologia cujo interesse era o de limitar 0 equipamento conceitual que pudesse ser usado em explicações psicológicas putativas, mas que não tinha particular interesse na análise do vocabulário mental da linguagem ordinária. Desta forma, a qualificação do filósofo com inclinações a esta tarefa é, até certo ponto, analógica. Considerando uma certa tendência de apropriação antecipada do termo 'behaviorismo', mesmo na psicologia, pelas posições defendidas por behavioristas radicais como Watson e Skinner, que requer que todas as generalizações psicológicas sejam definidas a partir daquilo que é observável, à medida que C. L. Hull pode ser classificado como um behaviorista, nossa classificação parece ter fundamento. A teoria de Hull, como a entendemos, é que os predicados mentais não são de maneira alguma 'elimináveis' em favor de predicados comportamentais, mas é condição para o seu emprego coerente, que eles sejam individualmente relacionados aos predicados comportamentais e que algumas destas relações sejam lógicas ao invés de empíricas, - um enfoque que é extremamente similar àquela que atribuímos a Wittgenstein" (FODOR, 1981, p. 319). Por behaviorismo lógico, Fodor entende "a doutrina de que há relações lógicas ou conceituais to tipo negado pela premissa cética (...). A forma mais forte do behaviorismo lógico sustenta que enunciados sobre estados mentais são traduzidos em enunciados sobre comportamento" (FODOR, 1981, p. 37). Para Fodor, Wittgenstein se enquadra em uma versão mais fraca, mas ainda assim, considera-o um behaviorista lógico. Uma exposição crítica sobre 0 behaviorismo lógico é feita por Fodor em The Language of Thought (FODOR, 1975, p. 2-5).

${ }^{6} O$ destaque das aspas tem a intenção de aludir 0 termo linguagem em sua acepção mais ampla, tal como uma combinação e manipulação de símbolos que são realizadas mediante regras. Quando uma linguagem é tomada em seu formato lógico e formal, como símbolos apenas, sem levar em conta seus significados, estamos falando do "mentalês". Já quando se trata da linguagem onde os símbolos são acompanhados com seus significados (as palavras propriamente ditas), necessitamos de atribuições da cultura à qual pertencemos. Nesse sentido é que falarmos uma língua natural como o português, 0 espanhol ou o inglês.
} 
de processos cognitivos), mas não para o segundo (o papel mediador da comunicação entre falantes e ouvintes); a línguas naturais são empregadas para o segundo, mas não para o primeiro.

$\mathrm{Na}$ perspectiva de Fodor, deve haver duas formas de linguagem: uma pública, constituindo as línguas naturais, e uma interna, puramente simbólica, responsável pela aquisição da linguagem natural. Fodor argumenta ainda que línguas naturais, como o português ou o inglês, seriam uma escolha equivocada para o formato representacional do "mentalês". As línguas naturais contêm várias ambigüidades, tanto do ponto de vista lexical como do ponto de vista estrutural e, por isso, não satisfazem as condições de representações mentais as quais devem ser explícitas quanto à sua forma lógica. A noção de uma linguagem interna e inata, a linguagem do pensamento, pressupõe a existência de representações mentais em forma de símbolos os quais são manipulados a partir de regras formais de cômputo. Assim sendo, a postura cognitivista Fodor procura sustentar a existência de estados internos como representacionais. Estes estados internos (estados mentais) são tomados como proposições e podem ser compreendidas mediante regras computacionais.

\section{Linguagem "Privada" do Pensamento}

A tese fodoriana de língua inata (ou o mentalês) é sua posição básica quanto à teoria da mente, uma vez que trata exclusivamente da sintaxe, deixando problema do conteúdo, a saber, o problema da semântica, de lado. O problema do conteúdo é reconsiderado por Fodor no início da década de 80, motivado por uma discussão com seu orientador Hilary Putnam a respeito do externalismo ${ }^{7}$, discussão esta que mencionaremos a seguir.

Fodor defende uma teoria de mente que, na esteira de Descartes e Chomsky, pressupõe a existência de estados mentais, de causalidade mental (eventos mentais possuem poderes causais) e de conteúdo informativo inato (mecanismos ou princípios que permitem aos indivíduos ao nascerem compreender a experiência e adquirir uma linguagem). Com estes três pressupostos, Fodor elabora uma concepção própria a respeito da linguagem e da cognição que se coloca veementemente contra a tradição wittgensteiniana, bem como o Positivismo Lógico de Gilbert Ryle. O problema central em seu programa de pesquisa é compreender os motivos

\footnotetext{
${ }^{7}$ Esclarecimentos sobre o externalismo podem ser muito bem obtidos em SILVA FILHO (2007).
} 
pelos quais fazemos as afirmações que fazemos a partir do equipamento mental que temos.

Fodor afirma existir uma "linguagem do pensamento", tendo como pressupostos quatro princípios heurísticos, a saber:

a) o estatuto psicológico de um sistema não depende de sua realização física, de seu hardware, e sim de seu software,

b) as representações mentais, a manipulação de símbolos, realizam e constituem as atividades cognitivas;

c) os símbolos com os quais a mente opera são entidades abstratas que não representam nenhuma relação de configuração com as entidades que denotam;

d) a "inteligência", os "estados mentais", podem ser realizados em sistemas independentemente de estruturas bioquímicas ou neurológicas.

O conjunto de pressupostos epistemológicos e princípios heurísticos dá corpo à principal tese do programa de pesquisa de Fodor, a saber, a existência de uma linguagem interna, a linguagem do pensamento. Tal tese tem como fundamento o argumento de que sistemas cognitivos envolvem representações e as operações cognitivas. As manipulações destas representações devem existir em algum lugar e serem manipuladas de alguma maneira. Este "algum lugar" e "de alguma maneira" é a linguagem base, ou o meio onde permite ocorrer o pensamento. Vale destacar que as representações são, enquanto operações cognitivas, de tipo simbólico e, por isso, de nível exclusivamente sintático.

A linguagem do pensamento constitui, segundo Fodor (1975), um meio muito produtivo que possibilita a execução de vários processos cognitivos como percepção, raciocínio e, ao nosso ver, o mais prioritário para a condição humana, a aprendizagem da língua. A linguagem do pensamento é, portanto, a condição para o aprendizado da língua, o que explica como uma criança adquire um amplo conjunto vocabular, que the permite uma comunicação satisfatória com falantes de mesma língua, em um curto prazo de tempo.

Uma resposta para a rapidez do aprendizado de uma língua já tinha sido apontada em 1957 por Chomsky (2002), em Syntactic Structures. Chomsky apresentou sua concepção inatista da linguagem ao argumentar que os humanos possuem, congenitamente, uma evidente inclinação para o aprendizado de uma língua: um dispositivo de "apreensão" da linguagem que permite sua aquisição. Tal dispositivo é biologicamente "pré-configurado". 
Basta perceber, conforme Chomsky, a rapidez e facilidade que as crianças demonstram para aprender uma língua: um fenômeno de características altamente abstratas. As pesquisas sobre a característica abstrata da linguagem, assim como seu processo de aprendizado, levaram Chomsky a sustentar uma posição mentalista. Para Chomsky, a explicação do caráter abstrato da linguagem exige necessariamente a retomada do conceito de mente, conceito que foi erradicado pelo behaviorismo. A constatação desta capacidade de construção e representação extremamente abstratas da linguagem levou Chomsky a uma segunda tese, a do inatismo: o aparato, ou melhor, o conjunto das etapas de funcionamento da linguagem é uma propriedade inata da mente humana. Por isso, a linguagem é metaforicamente um programa de computador, que tem seu funcionamento disparado pelos estímulos do meio, tese que estava na contramão do behaviorismo, especialmente a versão radical de Skinner. Para completar, Chomsky também chama a atenção para a dificuldade de modelização global dos processos cognitivos, sugerindo, assim, uma arquitetura modular da cognição: sua tese modular de mente ${ }^{8}$.

Este conjunto de teses mentalista, inatista e modular sugerido e argumentado por Chomsky, o tornou referência no meio acadêmico desde a metade do século XX, sendo por isso considerado como o principal responsável pela chamada revolução cognitiva 9 .

Enquanto Chomsky sustentava a tese de uma gramática profunda, a gramática gerativa, Fodor propõe, como dissemos, sua tese da linguagem do pensamento. Tal linguagem, na esteira de Chomsky, possui uma origem inata. A diferença entre estas teses está evidenciada na concepção sobre o que é inato. Para Fodor, o aparato intelectual inicial dos seres humanos constitui um conjunto completo de representações, sobre as quais formas novas de informação podem ser mapeadas quando o indivíduo está em contato com o mundo. Embora este aparato intelectual se apresente na "linguagem natural", não é em si uma linguagem natural. Outro seguidor de Chomsky, Pinker (2002), nomeia esta linguagem do pensamento de "mentalês", justificando que as pessoas não pensam nesta ou naquela língua do grupo lingüístico a que pertencem. As pessoas pensam, na verdade, em um língua do pensamento. Embora contenha semelhanças com as línguas naturais, o

\footnotetext{
${ }^{8}$ Sobre a tese modular de mente de Fodor, ver CANDIOTTO (2008).

${ }_{9}^{9} \mathrm{~A}$ responsabilidade pela identificação do feito de Chomsky, a revolução cognitiva, é principalmente do psicólogo George A. Miller, sugerindo ser o início deste período revolucionário em 11 de setembro de 1956, data do Simpósio sobre Teoria da Informação sediado pelo Massachusetts Institute of Technology. Gardner (2003) é considerado o principal divulgador desta identificação de Miller.
} 
"mentalês" é evidentemente mais rico em alguns sentidos e mais simples em outros. Sua riqueza se demonstra, por exemplo, pelo fato de vários símbolos conceituais se corresponderem a uma determinada palavra do idioma falado (PINKER, 2002).

Entretanto, a tese da linguagem do pensamento de Fodor coloca em questão o problema do significado, a saber, o problema da relação entre os símbolos e o mundo, e o vínculo entre eles estabelecido por representação.

\section{Símbolo e significado na Hipótese da Linguagem do Pensamento}

A posição básica de Fodor em teoria da mente, vale lembrar, não é acerca da semântica, mas da sintaxe "pura". Por isso, desenvolveu a chamada Hipótese da Linguagem do Pensamento. Para sustentar esta hipótese, Fodor afirma que os símbolos mentais usados para representar o mundo em nossos pensamentos são como sentenças (e não tanto como, por exemplo, fotos). Assim como as gramáticas de qualquer língua natural, como a portuguesa, não impõem nenhum limite para o número de sentenças que estão disponíveis para que alguém as enuncie, também a gramática do "mentalês" não limita a quantidade de pensamentos disponíveis. A sustentabilidade de tal tese está na necessária conexão entre psicologia cognitiva e lógica. O "mentalês" explica como a "forma lógica" das inferências pode afetar o curso do pensamento nos processos inferenciais. Para tanto, Fodor também conecta a psicologia cognitiva com a teoria da computação e faz isso ao explicar como os objetos mentais, como pensamentos e conceitos, podem dar domínios para processos mentais como o raciocínio. Mediante esta tese, é possível tratar os processos mentais como tipos de computações que são, por definição, operações formais definidas sobre as estruturas sintáticas das representações.

O tratamento computacional dos processos cognitivos é uma quebra radical com a tradição associacionista. A origem do associacionismo remonta $\mathrm{O}$ empirismo clássico de Locke e Hume, mas tem seu principal desenvolvimento com Ebbinghaus, Thorndike e, de forma peculiar, Skinner. Em A Modularidade da Mente, de 1983, Fodor menciona que a tradição associacionista pautou-se em quatro pressupostos na tentativa de explicação da teoria cognitiva. Primeiramente, o associacionismo leva em consideração um conjunto de elementos primários que compõem todas as estruturas psicológicas tais como a noção de reflexo, em uma perspectiva comportamentalista como a de Skinner, ou a noção de idéia, para os que defendem um caráter "mentalista" das estruturas psicológicas, como Hume. Como segundo pressuposto, o associacionismo prevê a existência de leis associativas que se aplicam à relação idéias/reflexos, produtos de associações, gerando uma distinção entre estruturas psicológicas elementares e 
complexas. Um terceiro pressuposto associacionista é o princípio da contigüidade espacial-temporal que concebe que a existência de certos princípios de leis associativas sobre a forma como a experiência empírica de um organismo determina quais elementos serão associados, ou seja, que idéias serão associadas ou que reflexos condicionados são formados. Por fim, um último pressuposto do associacionismo, identificado por Fodor (1983), é afirmação de parâmetros relevantes para as estruturas psicológicas relacionadas: relações associativas definidas por sua intensidade, como a repetição, para Hume, ou reflexos que se diferenciam em seu nível operante, para Skinner.

Por não admitir a existência de capacidades mentais (no plural), mas apenas a capacidade de fazer associações, o associacionismo é insuficiente para uma explicação das estruturas cognitivas. Fodor propõe que não existem faculdades como mecanismos causais, mas relações entre idéias e reflexos, de característica computacional, definindo o sistema cognitivo como um sistema computacional. $\mathrm{O}$ processo psicológico é compreendido como o resultado de transformações de representações mentais, sendo o sistema cognitivo a entidade capaz de levar realizar tais transformações (cf. FODOR, 1975, p. 164-169).

A teoria de que os processos mentais são computacionais depende da teoria de que as representações mentais são similares às sentenças, condição que o "mentalês" satisfaz; em particular, computações em que representações mentais têm estruturas constituintes. Embora os argumentos fortes para o "mentalês" destacados acima suportem a teoria de que pensamos através de algum tipo de linguagem, no entanto, ainda deixam em aberto que linguagem é esta. Mesmo que versões canônicas das teses da linguagem do pensamento sustentem que o "mentalês" é um sistema representacional não aprendido com muitas das propriedades formais de uma lógica, é possível sustentar uma versão menos polêmica: alguém poderia dizer que nós pensamos na linguagem que falamos, por exemplo, os falantes de inglês pensam em inglês, os falantes de português pensam em português. Tal identificação do "mentalês" com línguas naturais não é uma opção adequada. A consideração mais plausível é de que uma língua natural precisa ser aprendida presumivelmente por alguns tipos de inferências indutivas ou abdutivas ${ }^{10}$ sobre o que uma pessoa ouve em seu ambiente lingüístico. E, uma vez que tirar inferências é em si um tipo de pensamento, a teoria de que uma pessoa pensa em uma linguagem que tenha aprendido é destinada à circularidade: a identificação do mentalês com qualquer outra língua natural está fora de questão. Assim como Fodor, Pinker (PINKER, 1998, 2004) também entende que a hereditariedade e o ambiente desempenham importantes

${ }^{10}$ Sobre inferências indutivas ou abdutivas, ver FODOR (2001, p. 29). 
papéis para a aquisição de uma língua natural. Um indivíduo falará primeiramente a língua na cultura em que estiver inserido e, por isso, é evidente que o ambiente exerce um importante papel. Entretanto, se uma criança e um animal qualquer crescerem juntos, a criança falará uma língua, o que não ocorrerá jamais com este animal, exposto ao mesmo ambiente. Portanto, também é evidente que a hereditariedade desempenha um papel fundamental.

A linguagem do pensamento pode ser entendida como um dispositivo que opera sobre princípios puramente sintáticos e relações formais entre frases; relações só definíveis por referência às características sintáticas das frases, por análise componencial ${ }^{11}$. A teoria representacional da mente de Jerry Fodor descreve a mente como um aparelho capaz de realizar operações simbólicas e manipular símbolos, identificando assim as relações combinatórias existentes entre tais símbolos. Como dissemos, sua operação se dá apenas mediante princípios formais e sintáticos, isto é, sem levar em conta a significação destes símbolos. No entanto, esta afirmação implica dizer que as operações mentais, que processam as representações mentais, são cegas à semântica dos símbolos que manipulam, e suas manipulações são indiferentes a quem as manipula, dispensando assim os homúnculos que compreendem as significações dessas representações.

De acordo com a Teoria Representacional de Mente de Fodor, os processos mentais apenas podem ser compreendidos mediante uma abordagem sintática e, consequentemente, computacional ${ }^{12}$. Segundo esta concepção, a mente manipula representações mentais na forma de frases não interpretadas na linguagem do pensamento. $\mathrm{O}$ "não interpretado" significa que os processos pelos quais os símbolos são manipulados operam sem consideração pelas significações desses símbolos e, neste sentido, são concebidos como processos computacionais.

Fodor sugere com sua, a nosso ver, metáfora da "linguagem do pensamento", uma distinção entre símbolo e significado, uma vez que o significado de um símbolo não é intrínseco a este símbolo. O significado do símbolo não pertence a este símbolo, mas sim ao modo como o símbolo é

11 Entende-se por "análise componencial" o processo que visa constituir a configuração de unidades mínimas de significação (componentes semânticos ou traços semânticos) no interior da unidade lexical (morfema léxico ou palavra). A função da análise componencial é, portanto, isolar os componentes semânticos específicos de um termo da língua ou próprios da descrição de uma ocorrência dada de um termo da língua.

12 Recentemente, Fodor (2001) fez uma advertência: a noção de que todos os processos mentais são computacionais não é adequada e deve ser evitada. Fodor está dirigindo esta crítica à obra de S. Pinker, Como a Mente Funciona. Segundo Fodor, Pinker exagera ao reduzir os processos mentais ao computacional. Outros exageros de Pinker são: definir a arquitetura da mente como totalmente modular e entender que a teoria darwinista é suficiente para explicar nossa estrutura mental. 
disposto pelos agentes ou sistemas que dele dispõem. A atribuição de significações é uma atividade que pressupõe pensamentos com sentido, enquanto, na forma de "linguagem do pensamento", os pensamentos são abordados como símbolos e nada mais.

Seguindo seu projeto naturalista e procurando preservar a autonomia do mental, Fodor postula a existência de causalidade menta ${ }^{3}$. O problema da causalidade mental leva em conta a compreensão das "atitudes proposicionais". Apenas para esclarecimento, "atitudes proposicionais” são certos estados mentais intencionais, tais como desejo, crença ou vontade, que possuem um conteúdo (ou significado) proposicional próprio do sujeito. A sentença "eu quero ir à universidade", possui uma atitude proposicional (querer), a qual é uma atitude própria de um sujeito (eu) frente a uma proposição específica (ir à universidade). As atitudes proposicionais se apresentam no vocabulário intencional da folk psychology (psicologia popular), pois continuamente fazemos afirmações do tipo "penso que...", "creio naquilo", "quero tal coisa", "desejo tal questão", etc.. E, para Fodor (1990), os estudos sobre a cognição não têm atualmente condições de desconsiderar tal vocabulário. Por isso que, segundo o autor, é o "querer" o responsável causal do "alcançar", também a "crença" o responsável pelo "dizer”. Entretanto, continuando seu argumento, se estas relações forem literalmente falsas, nossa relação com o mundo não faz sentido, o que é o "fim do mundo" como o próprio Fodor menciona (1990, p. 156). De acordo com este conhecido comentário de Fodor, a causalidade mental é intuitivamente real, o que é atestado pela psicologia do senso comum ${ }^{14}$, e a negação de que o mental tem influência sobre o mundo foi um equívoco criado pelas ciências básicas (ciências experimentais, físicas). Causalidade mental, portanto, se refere a noção de que o comportamento é causado por eventos mentais, como desejos ou crenças. Negar tal influência, para Fodor, é um erro que os estudos atuais sobre a cognição não devem cometer.

Para Fodor, os estados mentais têm a capacidade de influenciar o comportamento humano e, conseqüentemente, o mundo. Da mesma forma, os estados mentais (o conteúdo das atitudes intencionais) de um sujeito são constitutivamente dependentes do ambiente externo deste sujeito. Essas

13 A questão da causalidade mental foi abordada pelo autor em sua literatura mais recente, especialmente Psychosemantics (p. 10ss), A Theory of Content (p. 19-29) e Hume Variations (p. 136ss). Neste trabalho não abordaremos aprofundadamente o problema da causalidade mental, por se tratar de um tema que merece um trabalho a parte, especialmente se remeter a um elemento a parte que é a noção das "atitudes proposicionais". O que iremos expor sobre a causalidade mental diz respeito à controvérsia da linguagem privada, que é o tema principal deste texto.

14 O emprego da folk psychology é alvo de muitas críticas, especialmente por CHURCHLAND (1981). 
noções constituem a tese externalista do conteúdo, já anunciada por Putnam em Representation and Reality. $\mathrm{O}$ externalismo ${ }^{15}$ constitui uma negação à concepção segundo a qual o conteúdo mental pode ser caracterizado plenamente com independência ao mundo externo. O externalismo é a perspectiva de que o conteúdo mental possui uma identidade relativa aos objetos e tipos de objetos do mundo, que são externos à mente. A noção de causalidade mental de Fodor complementa suas teorias de representação mental, uma vez que as leis psicológicas, que são intencionais, são implementadas por processos mentais sintáticos (computacionais), possibilitando uma ação do indivíduo sobre o mundo (uma resposta comportamental). Para Fodor, estados intencionais, como crenças e desejos, requerem símbolos para existirem. A razão disso é que os símbolos são os únicos portadores de significado ${ }^{16}$.

De acordo com a hipótese do "mentalês", o raciocínio é entendido como uma manipulação lógica e sintática de símbolos. Entretanto, as representações que se seguem às manipulações sintáticas não são aleatórias, pois precisam de uma adequação com o mundo, o referente, que é sua condição de verdade (truth-maker). Nesse sentido, a semântica, enquanto uma condição de verdade da representação, segue a sintaxe, a manipulação de símbolos que permite a representação.

A Teoria Representacional de Mente causa uma mudança na forma como as entidades mentais são concebidas. Até então, questões como crenças, desejos e intenções eram vistas apenas a partir de seu conteúdo qualitativo ou intencional. No entanto, a partir da Teoria Representacional proposta por Fodor, passam a ser tratadas como informações, encarnadas como configurações de símbolos, conectando assim o mundo do significado e da intenção com a matéria, com o cérebro: eis o que se denomina por materialismo mentalista.

A tradição wittgensteiniana, principalmente aquela promovida por Gilbert Ryle ${ }^{17}$, segundo Fodor, confundiu dualismo com mentalismo, bem como trouxe como consequência a oposição entre materialismo e mentalismo. De acordo com Fodor, "Ryle presume que um mentalista deve ser um dualista; particularmente, que o mentalismo e o materialismo sejam mutuamente excludentes" (1975, p. 04). Confundir mentalismo com dualismo é a principal falha, ao ver de Fodor, da tradição wittgensteiniana a

\footnotetext{
15 Um esclarecimento sobre o externalismo pode ser muito bem identificado em SILVA FILHO (2007).

16 Lembrando que símbolo e significado são distintos entre si e mutuamente dependentes, constituindo 0 que Fodor (1990) denomina por "dependência assimétrica".

${ }^{17}$ Notadamente em sua obra The Concept of Mind de 1949.
} 
qual promoveu uma série de impasses para uma teoria da mente. Para que seja possível uma filosofia da psicologia, segundo Fodor (1975, 2001), deve-se assumir uma atitude anti-wittgensteiniana e adotar o que podemos chamar de "materialismo mentalista", ou seja, a ideia de que os processos mentais podem ser compreendidos mediante a lógica computacional. É importante esclarecer que "materialismo mentalista" não implica em dizer que os estados mentais são materiais, mas que a linguagem do pensamento, enquanto um processo mental, caracteriza-se pela sua lógica combinatória, assim como se identifica na máquina computacional (computador) ${ }^{18}$.

Para Fodor, é comum no domínio do mental a causação entre eventos, pois comportamentos são resultados, de certa forma, das crenças (causalidade mental) do agente da ação. O que justifica a ação (comportamento) de um indivíduo ingerir um medicamento, por exemplo, é explicado levando em consideração a existência de um conjunto de crenças, desejos e intenções responsáveis por esta ação: o desejo de livrar-se da dor, intenção de ingerir um medicamento, a crença que algum remédio resolverá esta intenção, e outras questões mentais possíveis. Entretanto, o que Fodor pretende afirmar é a interação entre estados mentais e comportamentos e que a explicação para tal interação está na aceitação de um domínio natural da teorização psicológica que inclua sistemas cognitivos que processem informação e que se realizam internamente no sujeito da ação.

Símbolos ou cadeias de símbolos são estados físicos de bits de matéria que representam coisas do mundo e são disparados por estas coisas via órgãos sensoriais. Os símbolos, por exemplo, correspondentes a uma crença, podem ser ajustados de tal modo que originam novos símbolos correspondentes a outra crença. Existem símbolos mentais que são representações mentais e que pressupõem propriedades semânticas. Ter uma crença envolve uma relação com um símbolo mental; a crença, por sua vez herda suas propriedades semânticas do símbolo mental que aparece na relação. Os processos mentais (perceber, aprender...) envolvem interações causais entre estados relacionais, tais como ter uma crença. Por sua vez, as propriedades semânticas das palavras e sentenças que proferimos são herdadas das propriedades semânticas dos estados mentais que a linguagem expressa. A associação entre propriedades semânticas dos estados mentais e propriedades dos símbolos mentais sugere a metáfora computacional, a saber, a comparação com a

\footnotetext{
18 Lembrando novamente que Fodor não compartilha da ideia de que todos os processos mentais podem ser compreendidos nos moldes da Teoria Computacional (FODOR, 2001). No entanto, sua tese da Linguagem do Pensamento, sim, deve ser tomada como um intermédio de representações internas ao sujeito, sobre as quais se definam as computações. Para melhores considerações, ver Miguens (2002).
} 
manipulação de símbolos operada pelo computador, que leva em conta fórmulas semanticamente interpretadas baseadas em um código da máquina. Isto explica a afirmação de Fodor (1975, p. 31) que sem computação não há representação, o que implica na existência de símbolos mentais, resultado da analogia entre o processamento mental e processamento computacional.

É possível afirmar, então, que Fodor não reduz o pensamento a seu aspecto sintático. Os processos mentais, que são sintáticos, permitem a existência das leis psicológicas que têm uma relação com o mundo, isto é, que farão sentido no mundo. Eis, portanto, o aspecto semântico dos estados mentais que o próprio Fodor reconhece existir, mas que é inacessível à nossa compreensão. $\mathrm{O}$ que podemos compreender sobre os estados mentais é seu aspecto sintático (processos), e não o semântico (conteúdo das representações). Essa separação, para Fodor, é metodológica, resultando no conhecido princípio do solipsismo metodológico (FODOR, 1974) e, por isso, a psicologia que trata Fodor é de processos e não de conteúdo. A psicologia cognitiva não possui condições de explicar a referência das representações ao mundo exterior. A crença na "expiação" de suas "culpas", por exemplo, pode causar a ida de um sujeito até a igreja para "confessar" seu "pecado" à autoridade religiosa. Independentemente se essa "expiação" for real ou não, a "crença”, contudo, existe. O comportamento desse sujeito é resultado não da "expiação", mas de sua crença, o que explica seu propósito de ir até a igreja. Não é preciso algo externo ao sujeito para explicar a causa seu comportamento, mas apenas as informações que ele obteve, assim como suas representações e as regras com que ele as manipula.

Essa perspectiva metodológica de Fodor estabelece uma separação entre semântica e sintaxe, cabendo aos estudos sobre a cognição apenas a sintaxe, pois é vedado o acesso objetivo aos significados das representações. Não significa com isso que as representações mentais não tenham propriedades semânticas, mas apenas que não estão ao alcance da investigação científica. A solução deste problema do significado das representações, o problema propriamente semântico, ainda é um dos objetivos do programa de pesquisa de Fodor ${ }^{19}$.

Em suas primeiras obras, Fodor elaborou uma teoria sobre a mente que manteve uma posição exclusivamente sintática. Até o início da década de 80, principalmente com a obra The Modularity of Mind: An Essay on Faculty Psychology de 1983, a posição de Fodor acerca da mente era

\footnotetext{
${ }^{19}$ Esta metas de seu programa de pesquisa podem ser identificadas em obras como Psychosemantics (1987), The Elm and the Expert (1994), Concepts: Where Cognitive Science Went Wrong (1998), The Mind Doesn't Work That Way (2000) e Hume Variations (2003).
} 
basicamente sintática. Mas seu interesse pela questão da semântica já é manifestado em seu artigo de 1980, Methodological Solipsism as a Research Strategy. Entretanto, em face aos apelos de Putnam (1975, p. 223-227) ao externalismo, especialmente com a exposição do experimento mental da "Terra Gêmea"20, inicia-se uma preocupação com a questão da semântica, motivo pelo qual Fodor defende o solipsismo metodológico como estratégia de investigação para a teoria psicológica.

A estratégia metodológica é, por princípio, tomar os estados psicológicos de forma individualizada, sem levar em conta sua avaliação semântica, aproximando-se assim ao internalismo. Essa aproximação de Fodor ao internalismo é apenas na questão metodológica, para compreensão dos processos mentais enquanto manipulação de símbolos. A partir dos debates com Putnam, Fodor reconhece que os processos internos do cérebro não são suficientes para determinar a significação do conteúdo mental, pois é preciso estabelecer uma relação entre mente e mundo. No entanto, é prudente que a pesquisa sobre a identidade do conteúdo mental, segundo Fodor, adote tal postura solipsista.

Fodor, ao propor o solipsismo metodológico como uma estratégia de pesquisa dos estados mentais, não nega a semântica, nem retira sua importância para a explicação psicológica. No entanto, o acesso objetivo aos significados das representações ainda não está ao alcance da ciência básica (ciências experimentais), cabendo uma abordagem especial, uma ciência especial21. O objetivo dessa ciência especial é explicar os estados mentais,

\footnotetext{
${ }^{20}$ A noção de solipsismo metodológico de Fodor é uma tentativa de resolver os problemas pertinentes ao conhecido experimento mental da "Terra Gêmea" de Putnam (1975, p. 223-227) em relação ao externalismo. Resumidamente, o experimento mental da "Terra Gêmea" diz o seguinte: vamos supor que exista outro planeta aparentemente idêntico ao nosso, uma Terra-Gêmea, e que neste planeta, a água que conhecemos não fosse composta por $\mathrm{H} 2 \mathrm{O}$ e sim por $\mathrm{XYZ}$. Apenas sua composição é diferente, contendo todas as outras características da água do planeta Terra e, inclusive, os habitantes desta Terra-Gêmea a chamam também de "água". A única coisa diferente entre estes planetas é a composição da água. Neste planeta há também uma réplica perfeitamente igual a um terráqueo humano. Por serem idênticos, teriam estados psicológicos internos como crenças e desejos também idênticos. No entanto, haveria mesmo assim uma atitude proposicional que continuaria distinta, a saber, que a água é $\mathrm{H} 2 \mathrm{O}$ : para o terráqueo é verdadeira, para a réplica da Terra-Gêmea é falsa. Mesmo com todos os estados internos iguais, eles crêem em proposições diferentes. Sendo assim, Putnam conclui que o ambiente externo é um dos determinantes das atitudes proposicionais.

${ }^{21}$ Fodor expõe o termo "ciência especial" com a intenção de se precaver do reducionismo positivista. Para ele, a psicologia deve ser considerada uma ciência intencional e, por isso, especial. Seu intuito é diferenciá-la da ciência básica (a física, especialmente), que possui leis estritas, isto é, leis "sem exceção". Uma ciência intencional, como a psicologia, não se exerce com leis estritas, mas com leis (cláusulas) ceteris paribus. Essa diferenciação é apresentada por Fodor (1974; 1975), onde se contrapõe à perspectiva que ele considera equivocada da filosofia da ciência positivista: exigir que as ciências especiais como a psicologia tenham que se reduzir a teorias físicas.
} 
levando em conta a psicologia do senso comum (folk psychology) e admitindo a existência de leis psicológicas causais. Fodor não toma o solipsismo como imediatamente verdadeiro, mas que a verdade, a referência, e o restante das noções semânticas não são categorias psicológicas. Para Fodor, tais categorias são formas de existência, ou como ele mesmo menciona, formas do Dasein. "Não sei o que é o Dasein, mas tenho certeza que existe muito por aí” (FODOR, 1990, p. 56).

\section{Considerações Finais}

Os principais desafios da hipótese da "linguagem do pensamento" de Fodor foram e ainda são provenientes da possível confusão entre "linguagem natural" e "linguagem privada", mas especificamente sobre o entendimento do que é "privado". Por isso, uma distinção deve ser feita quanto à concepção de "linguagem" entre as abordagens wittgensteiniana e fodoriana. Enquanto Wittgenstein compreendia a linguagem exclusivamente como um instrumento de comunicação que apenas se realiza mediante palavras "materializadas" em sua forma escrita ou sonora, Fodor concebe a linguagem em um duplo aspecto: uma linguagem como um sistema de representações (a linguagem do pensamento propriamente dita) que permite, com o contato com a cultura, a existência da linguagem natural, com suas palavras escritas ou sonoramente existentes.

A tradição wittgensteiniana rotula como "privado" aquelas questões que apenas o sujeito tem acesso de entendimento (que apenas ele pode entender e os demais não), enquanto a noção fodoriana diz respeito a tudo o que é interno, no caso, o médium de representações (linguagem do pensamento) e seu processamento. Para Fodor, o processo que é interno, e não o conteúdo das representações, os quais dependem do contexto externo do indivíduo. Isto explica a diferença de estratégias de estudo entre tais perspectivas, uma vez que os processos mentais, na abordagem wittgensteiniana, só poderiam ser investigados mediante critérios externos, manifestados no comportamento do sujeito. Na contramão, Fodor procurou (e procura) estabelecer um programa de pesquisa voltado aos processos mentais enquanto tais, tomando-os como computacionais.

Os desafios para sustentar a tese da linguagem do pensamento impuseram a Fodor a elaboração de argumentos e diálogos que aprofundaram a questão do problema semântico da linguagem, a saber, o problema do significado. Como resultado, temos a discussão entre externalismo e internalismo que, a nosso ver, intensificam ainda mais o dilema da questão. 
Fodor, motivado por Chomsky, concentrou sua investigação principalmente na dimensão sintática da mente. Entretanto, a dimensão semântica ainda é sua principal limitação, mesmo que a tese da linguagem do pensamento tenha contribuído para o avanço das pesquisas em Ciências Cognitivas, devido sua função heurística. Como avanço principal, temos a reafirmação da existência de processos mentais com poderes causais, como uma continuidade ao mentalismo chomskyano e fortificação à "revolução cognitiva" (GARDNER, 2003). A tese da linguagem do pensamento, mesmo perante a resistência teórica proporcionada pela tradição wittgensteiniana, contribuiu para a reconsideração da existência dos processos mentais como objeto de estudo da pesquisa psicológica. $\mathrm{O}$ alcance dessa explicação ainda faz parte do projeto de pesquisa de Fodor e, consequentemente, o desafio dos estudos sobre a cognição.

\section{Referências bibliográficas}

ANDLER, D. (Org). Introdução ìs ciências cognitivas. Trad. Maria Suzana Marc Amoretti. São Leopoldo: Ed. Unisinos, 1988.

CANDIOTTO, K. B. B. "Fundamentos epistemológicos da Teoria Modular da mente de Jerry A. Fodor”. In: Trans/Form/Ação, São Paulo, vol. 31, n. 2, p. 119-135, 2008.

CHIHARA, C.; FODOR, J. "Operationalism and ordinary language: a critique of Wittgenstein”. In: American Philosophical Quarterly, 2, p. 281295, 1965.

CHOMSKY, N. Syntactic Structures. New York : Mouton de Gruyter, 2002.

CHURCHLAND, P. M. (EMPA). "Eliminative Materialism and Propositional Attitudes”. In: Journal of Philosophy 78, n⿳亠丷a 2, p.67-90, 1981.

FODOR, J. A. A theory of Content and Other Essays. Cambridge Massachusetts: The MIT Press, 1990.

. Concepts: Where Cognitive Science Went Wrong. Oxford: Oxford University Press, 1998. . Hume Variations. Oxford: Oxford University Press, 2003. "Methodological Solipsism Considered as a Research Strategy". In: Cognitive Psychology. Behavioral and Brain Sciences, 3, p. 63-73, 1980. . Psychological Explanation: An Introduction to the Philosophy of Psychology. New York: Random House, 1968.

. Psychosemantics. The Problem of Meaning in the Philosophy of Mind. Cambridge, Massachusetts: The MIT Press, 1987.

1981.

. Representations. Cambridge, Massachusetts: The MIT Press, 
. The Elm and the Expert: Mentalese and Its Semantics. Cambridge, MA: MIT Press, 1994.

. The Language of Thought. Cambridge, Massachusetts: Harvard University Press, 1975

. The Modularity of Mind. Cambridge, Massachusetts: The MIT Press, 1983.

The Mind Doesn't Work That Way. The Scope and Limits of Computational Psychology. Cambridge, Massaschusetts: The MIT Press, 2001.

. "Special sciences, or the disunity of science as a working hypothesis”. In: Synthese 28, p. 97-115, 1974.

. \& KATZ, G. The Structure of Language. Prentice-Hall, 1964.

GARDNER, H. A nova ciência da mente. $3^{\circ}$ ed. São Paulo: EDUSP, 2003.

MIGUENS, S. Uma Teoria Fisicalista do Conteúdo e da Consciência: D. Dennett e os debates da filosofia da mente. Porto: Campo das Letras, 2002.

PETZOLD, C. The Annotated Turing: A Guided Tour through Alan Turing's Historic Paper on Computability and the Turing Machine. Indiana : Wiley Publishing, 2008.

PINKER, S. Como a Mente Funciona. São Paulo: Companhia das Letras, 1998.

PUTNAM, H. The meaning of "meaning". In: PUTNAM, H. Philosophical Papers, Vol. 2: Mind, Language and Reality. Cambridge University Press, 1975.

RYLE, G. The Concept of Mind. Londres: Routledge, 2009.

SILVA FILHO, W. J. da. "Mente, mundo e autoconhecimento: uma apresentação do externalismo". In: Trans/Form/Ação, São Paulo, 30(1), p. 151-168, 2007.

TURING, A. "On Computable Numbers, with an Application to the Entscheidungsproblem". In: Proceedings of the London Mathematical Society, 2nd series, Vol. 42, p. 230-265, 1936.

WITTGENSTEIN, Ludwig. Investigações filosóficas. Trad. J. C. Lourenço. Lisboa: Fundação Calouste Gulbenkian, 1987. 